\title{
19. ORGANIC MATTER IN DEEP SEA DRILLING PROJECT SITE 504 AND 505 SEDIMENTS STUDIED BY A THERMAL ANALYSIS-GAS CHROMATOGRAPHY TECHNIQUE1
}

\author{
Jean K. Whelan and John M. Hunt, Woods Hole Oceanographic Institution, Woods Hole, Massachusetts
}

\begin{abstract}
Sediments from Deep Sea Drilling Project Sites 504 and 505 near the Costa Rica Rift were examined by thermal methods. It was found that production index (P.I.) values, which measure the degree of thermal hydrocarbon generation in the sediment, were slightly different for the two sites when compared for sediments with similar types of organic matter. Highly burrowed sections of these immature sediments gave anomalously low values of pyrolyzable hydrocarbons, suggesting production of inert organic carbon by purely biological processes. Organic carbon levels correlate with pyrolyzable hydrocarbons at both sites and show that samples with less than $1 \%$ organic carbon are inert to hydrocarbon generation under any conditions of time and temperature.
\end{abstract}

\section{INTRODUCTION}

Samples recovered from Sites 504 and 505 near the Costa Rica Rift provide an opportunity to examine the effects of different geothermal regimes on organic matter from very similar sediments. Sediments at the two sites appeared to be alike in age, mineral composition (predominantly diatomaceous ooze), and depth (240 m) (Beiersdorf and Natland, this volume). The major difference between the two sites is believed to be the maximum temperature to which the sediments in each have been exposed in the past: $59^{\circ} \mathrm{C}$ in the case of Site 504 and $9^{\circ} \mathrm{C}$ in the case of Site 505 (site chapters, this volume). The maximum temperatures are also believed to be the current bottom hole temperatures. Pyrolysis-gas chromatography studies were carried out on sediments from the two sites to determine whether the different geothermal regimes at the two sites caused differences in the sedimentary organic material.

One quantity that might be expected to differ in the two holes as a result of the different geothermal regimes is the amount of absorbed thermally generated petroleum hydrocarbon. The maximum temperature to which the sediments at Site 504 are believed to have been exposed $\left(59^{\circ} \mathrm{C}\right)$ is near the minimum believed to be necessary to initiate significant petroleum hydrocarbon generation in marine sediments (Hunt, 1979, p. 146). At this temperature, the amount of absorbed free hydrocarbon in the sediment begins to show an exponential rise above the trace amounts generally present in shallower sections. In addition, for petroleum generation to occur the organic matter present in the sediments must be of the proper type and amount. The minimum amount of organic matter necessary is generally cited in the literature as being in the range from 0.5 to $2 \%$, although smaller values can produce traces of hydrocarbons in sediments (Hunt, 1979, p. 154). The sediments at Sites 504 and 505 contain 1 to $3 \%$ organic carbon. The generation process al-

\footnotetext{
1 Cann, J. R., Langseth, M. G., Honnorez, J., Von Herzen, R. P., White, S. M., et al.,
} Init. Repts. DSDP, 69: Washington (U.S. Govt. Printing Office). so requires that the organic matter be of the proper type. For example, sapropelic marine organic matter tends to produce more hydrocarbon at lower temperatures than more humic terrigenous material (Tissot and Welte, 1978; Hunt, 1979, pp. 274-277 and refs. cited therein). Time is also a factor. Younger sediments (Pleistocene) require higher temperatures than older (e.g., Cretaceous) ones for equivalent amounts of hydrocarbon to form. The sediments must also have never been exposed to very high temperatures $\left(>200^{\circ} \mathrm{C}\right)$, which would cause thermal degradation and migration of the hydrocarbons.

The use of thermal analysis methods, such as the popular Rock Eval pyrolysis (Espitalié et al., 1977), to examine geothermal hydrocarbon production has become widespread in recent years (Giraud, 1970; Barker, 1974; and Claypool and Reed, 1976). The method used in this work was thermal distillation-pyrolysis-gas chromatography (TDPGC) (Whelan et al., 1980; Huc and Hunt, 1980; Whelan and Hunt, in press). A small sample of sediment is heated at a rate of $60^{\circ} \mathrm{C} / \mathrm{min}$. from $120^{\circ}$ to $700^{\circ} \mathrm{C}$ to produce a trace (called a pyrogram) of the amount of hydrocarbon versus temperature (Fig. 1). The pyrogram typically shows two clearly separated peaks. The low temperature peak, $\mathrm{P}_{1}\left(100-250^{\circ} \mathrm{C}\right)$ is a measure of the free and absorbed hydrocarbons that occur in the sediment and are driven out by thermal distillation. The high temperature peak, $\mathrm{P}_{2}\left(400-700^{\circ} \mathrm{C}\right)$ is a measure of the hydrocarbons cracked by pyrolysis from the complex high molecular weight organic material. Thus, $\mathrm{P}_{2}$ gives a measure of the hydrocarbons that could be generated if a particular sediment were subjected to higher geothermal temperatures for longer periods of time.

A quantity called the production index (P.I.) has been used to show how far petroleum generation has progressed in a particular sediment (Espitalié et al., 1977; Barker, 1974; Huc and Hunt, 1980). This quantity is defined as $\mathrm{P}_{1} /\left(\mathrm{P}_{1}+\mathrm{P}_{2}\right)$. Values of 0.1 or less generally occur in young, immature sediments, while values greater than 0.1 are typical of sediments that have been subjected to temperatures greater than $50^{\circ} \mathrm{C}$. Very high values indicate migrated hydrocarbons, especially when they accom- 


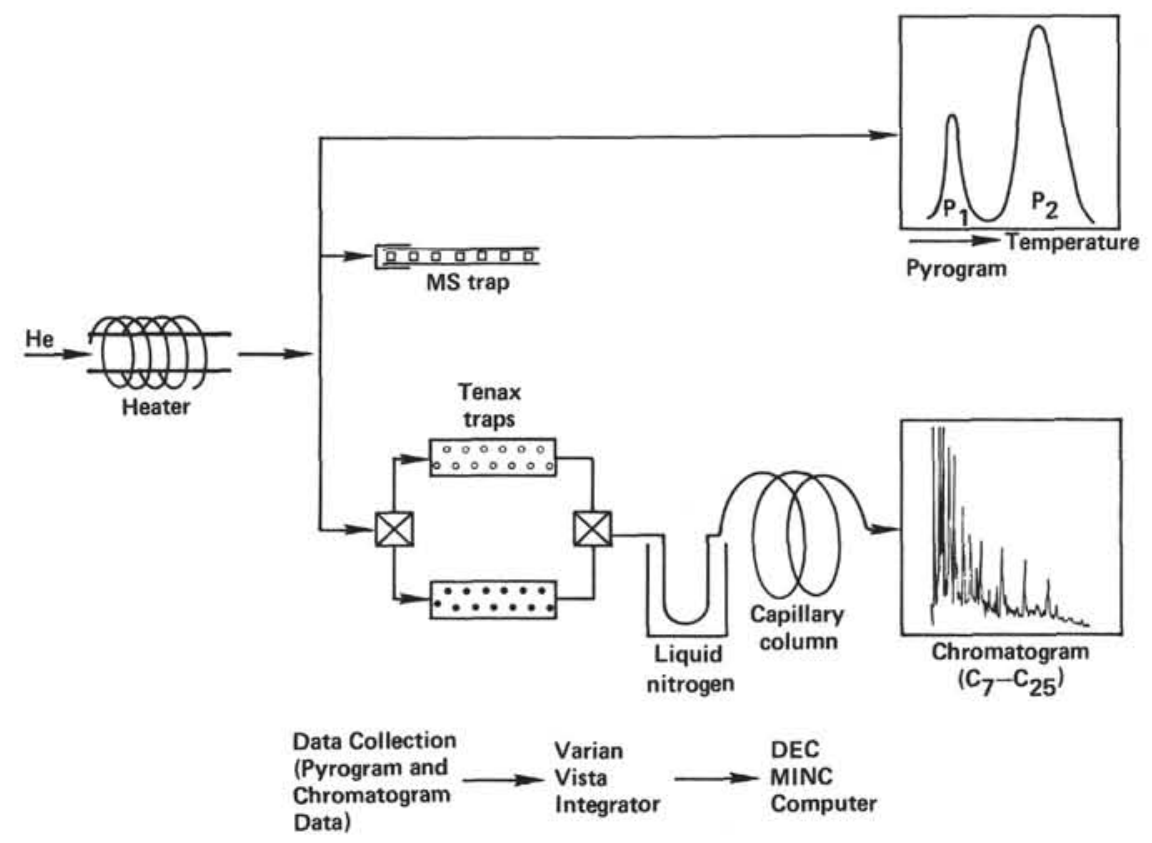

Figure 1. Diagram of TDPGC apparatus. MS denotes mass spectrometer trap.

pany a low $P_{2}$ and a high $P_{1}$. In this work, an attempt was made to use the P.I. as a measure of the geothermal history of these young sediments. Some of the complications encountered during this attempt point to some potential problems in applying P.I. alone as a petroleum source rock thermal maturation indicator. Specifically, differences in past sediment biological activity appear to affect the P.I. significantly.

\section{METHODS}

The technique used herein was previously described by Whelan et al. (1980). The thermal analysis apparatus was devised in this laboratory from components purchased from Chemical Data Systems (Oxford, $\mathrm{Pa}$ ). Subsequently, Chemical Data Systems marketed a complete system (the 820 Geological Reaction System) that carries out the analysis more automatically, and this system was incorporated in our apparatus. A schematic representation of the instrument used in this work is shown in Figure 1 . The wet sample, coarsely crushed (1-50 $\mathrm{mg}$ ), is heated at a rate of 60 or $120^{\circ} \mathrm{C} / \mathrm{min}$. from 120 to $700^{\circ} \mathrm{C}$ in the platinum coil of a pyrolysis probe. As temperature increases the compounds released are swept out of the sample in a stream of helium. One-tenth of the stream is directed toward a flame ionization detector, so the yield of hydrocarbons with respect to time (or temperature) can be monitored. The resulting output is called a pyrogram. The other fraction is swept through the lines that are inside the Reaction System oven, which is kept heated at $300^{\circ} \mathrm{C}$. This helium stream is then directed into one of the two Tenax traps (60-80 mesh, Applied Scientific Co.). By turning a valve, $P_{1}$ and $P_{2}$ can be trapped separately during the analysis. At room temperature, the Tenax trap absorbs $C_{7}$ and higher hydrocarbons but does not retain water. When the traps are heated, the trapped compounds are swept into a precolumn loop cooled with liquid nitrogen in order to reduce sample volume before the sample is injected into the gas chromatography (GC) capillary column $(50 \mathrm{~m} \times 0.50 \mathrm{~mm}$ I.D. OV101, stainless steel, Analabs, Inc.). The sample is analyzed by programming the GC column to heat at $6^{\circ} \mathrm{C} / \mathrm{min}$. from $60^{\circ} \mathrm{C}$ to $240^{\circ} \mathrm{C}$. All valve turning and trap heating is carried out automatically via a programmable timer connected to the 820 Reaction System. The integration of both pyrogram peaks and capillary GC peaks is carried out with a Varian Vista 401 Chromatography Data system that is interfaced with a Digital Instrument Corporation MINC LSI 11/23 computer system. The method is standardized by running a known mixture of pure hydrocarbons from $\mathrm{C}_{7}$ up to
$\mathrm{C}_{20}$. Individual compounds in both the known mixture and the subsequently tested samples were identified by their $\mathrm{GC}$ retention times.

Production index data are shown in Figures 2 to 4 . Figure 2 shows the averages of three analyses together with error bars for one standard deviation. The analyses were carried out over a 4-week time period. Data from the third analysis were used in plotting Figures 3 and 4. It can be seen that the minor differences between the P.I. in Figures 3 and 4 as compared with Figure 2 are within the error (standard deviation) of the method.

Carbon content was determined by combustion (a LECO Apparatus was used). Organic carbon was measured on previously decarbonated rock. Both total carbon and organic carbon were measured (Table 1, Figs. 3 and 4$)$.

\section{RESULTS AND DISCUSSION}

Average values and standard deviations for three determinations of P.I. for Sites 504 and 505 are shown in Figure 2. The values at the geothermally colder site (Site $505)$ are generally 0.1 or less, as expected for these shallow (maximum sub-bottom depth: $236 \mathrm{~m}$ ) sediments. As shown in the figure, the current bottom hole temperature is $9^{\circ} \mathrm{C}$. The production index value in the surface sample, which is 0.38 , is anomalously high. The analysis of the composition of $\mathrm{P}_{1}$ from the capillary GC pattern indicates that the high value of P.I. is not due to contamination. Some higher values of P.I. occur in the deepest samples, with an almost linear increase in the bottom four samples. Site 504, in contrast, shows a gradual increase in P.I. below 80 meters. The current bottom hole temperature for this site is $59^{\circ} \mathrm{C}$. However, there is a drop in P.I. in the deepest samples, which have been exposed to the highest temperatures. Production index values at Site 504 are generally higher than those at Site 505. The scatter of data in the shallowest samples at Site 504 (depths less than $50 \mathrm{~m}$ ) and the shallowest sample at Site 505 may be typical of very young sediments. The technique has not previously been applied to surface sediments, where the quantity of (1) biological 


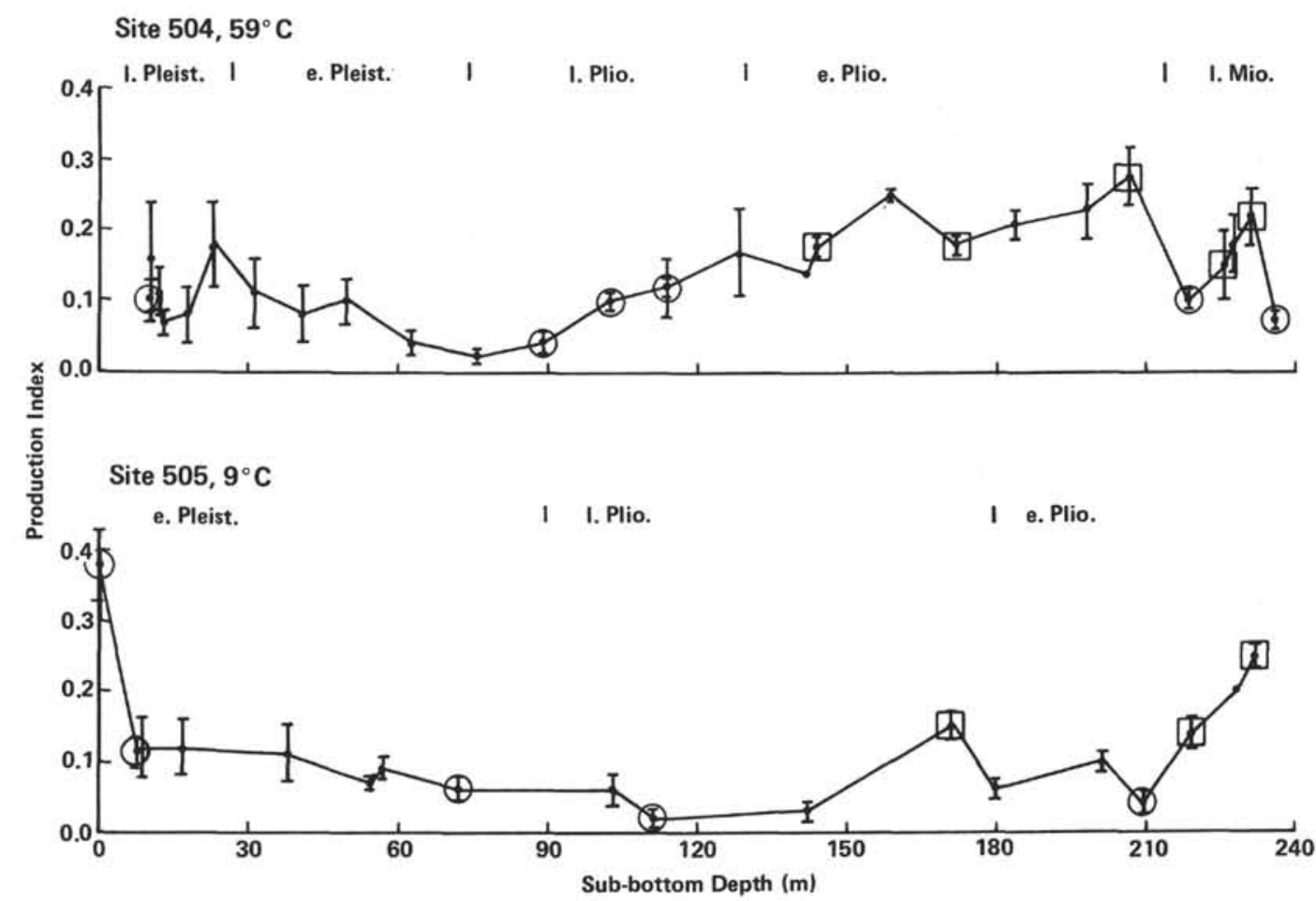

Figure 2. Production index as a function of depth for Sites 504 and 505. Circles indicate samples with similar capillary gas chromatography $P_{2}$ patterns as shown in Figure 5. Boxes indicate samples with $P_{2}$ capillary GC patterns different from those indicated with circles (e.g., see Fig. 4).

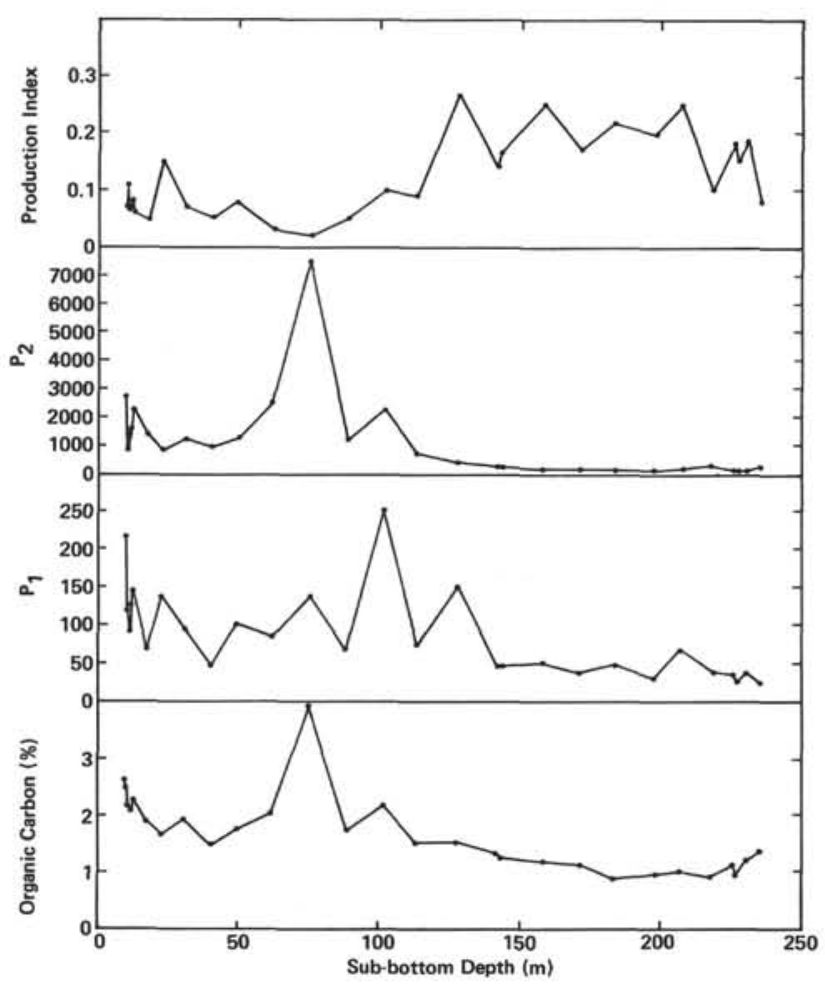

Figure 3. Variation of P.I., $P_{2}, P_{1}$, and organic carbon with depth for Site 504. $P_{1}$ and $P_{2}$ yields are in micrograms of hydrocarbon per $g$ dry weight sediment.

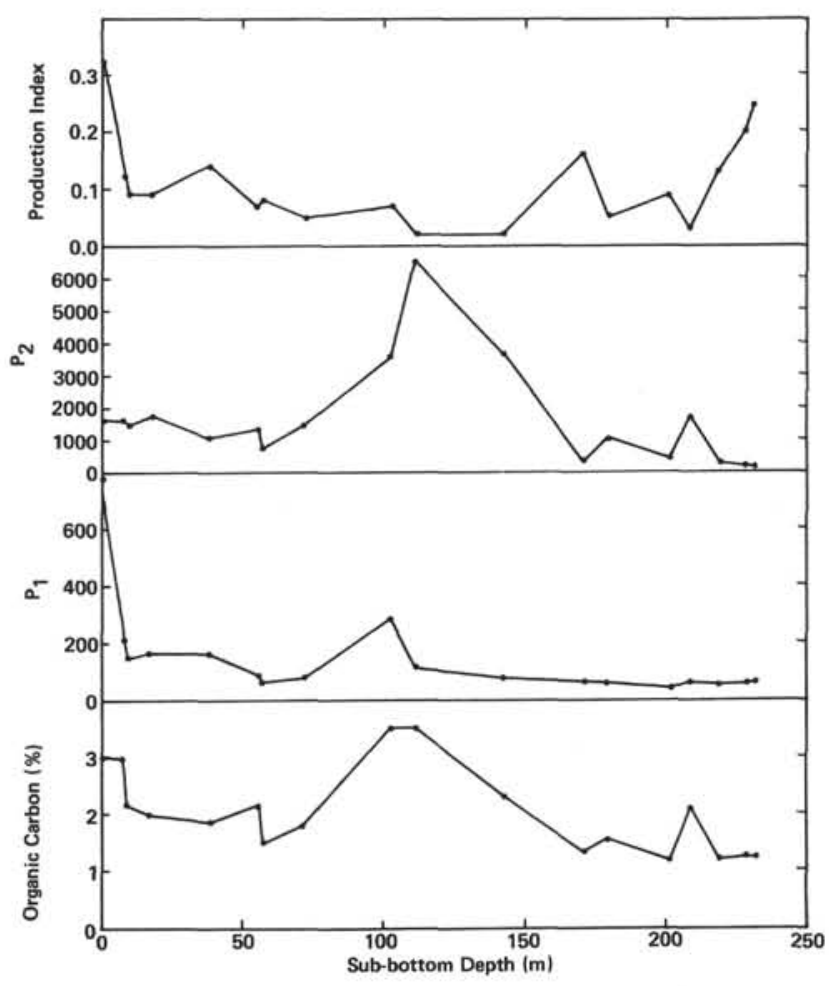

Figure 4. Variation of P.I., $P_{2}, P_{1}$, and organic carbon with depth for Site 505. $P_{1}$ and $P_{2}$ yields are in micrograms of hydrocarbon per $g$ dry weight sediment. 
Table 1. Percent total and organic carbon in sediments from Sites 504 and 505.

\begin{tabular}{|c|c|c|c|}
\hline Sample & $\begin{array}{l}\text { Sub-bottom } \\
\text { Depth (m) }\end{array}$ & Total Carbon $(\%)$ & Organic Carbon $(\%)$ \\
\hline $504-1-1,8 \mathrm{~cm}$ & 10.1 & $5.03 \pm 0.04$ & 2.60 \\
\hline $1-1,67$ & 10.7 & $2.99 \pm 0.01$ & $2.48 \pm 0.02$ \\
\hline $1-1,142$ & 11.4 & $5.13 \pm 0.01$ & 2.18 \\
\hline $1-2,58$ & 12.1 & $3.64 \pm 0.05$ & $2.11 \pm 0.04$ \\
\hline $1-2,147$ & 13.0 & $6.72 \pm 0.03$ & $2.29 \pm 0.02$ \\
\hline $2-3,55$ & 18.0 & $6.30 \pm 0.10$ & $1.89 \pm 0.01$ \\
\hline $3-3,127$ & 23.1 & $5.93 \pm 0.10$ & $1.66 \pm 0.06$ \\
\hline $5-3,46$ & 31.1 & $3.29 \pm 0.02$ & 1.94 \\
\hline $7-3,147$ & 40.9 & $8.37 \pm 0.01$ & $1.47 \pm 0.04$ \\
\hline $9-3,116$ & 49.4 & $5.82 \pm 0.03$ & $1.75 \pm 0.01$ \\
\hline $12-3,14$ & 62.5 & $7.07 \pm 0.01$ & $2.05 \pm 0.01$ \\
\hline $15-3,111$ & 75.7 & $4.14 \pm 0.03$ & $3.91 \pm 0.10$ \\
\hline $18-3,102$ & 88.8 & $7.14 \pm 11$ & 1.76 \\
\hline $21-3,140$ & 102 & $4.31 \pm 0.01$ & $2.21 \pm 0.07$ \\
\hline $24-2,76$ & 113.5 & $6.39 \pm 0.05$ & $1.52 \pm 0.03$ \\
\hline $27-3,87$ & 128.3 & $5.69 \pm 0.01$ & $1.54 \pm 0.03$ \\
\hline $31-1,4$ & 142 & $5.95 \pm 0.10$ & 1.34 \\
\hline $31-1,148$ & 143.5 & $7.78 \pm 0.06$ & $1.27 \pm 0.01$ \\
\hline $34-2,29$ & 158.5 & $7.79 \pm 0.04$ & $1.20 \pm 0.03$ \\
\hline $37-3,23$ & 171.6 & 8.96 & $1.15 \pm 0.04$ \\
\hline $40-2,68$ & 183.8 & $8.55 \pm 0.01$ & 0.90 \\
\hline $43-3,130$ & 198.3 & $9.57 \pm 0.04$ & 0.98 \\
\hline $46-1,143$ & 207.4 & 8.78 & $1.03 \pm 0.01$ \\
\hline $49-1,47$ & 218.5 & $9.55 \pm 0.01$ & 0.94 \\
\hline $51-1,6$ & 226.1 & $8.03 \pm 0.04$ & $1.14 \pm 0.03$ \\
\hline $51-2,4$ & 227.5 & $9.57 \pm 0.04$ & $0.95 \pm 0.01$ \\
\hline $52-1,104$ & 231 & $8.66 \pm 0.06$ & $1.23 \pm 0.04$ \\
\hline $53-2,16$ & 235.7 & $6.55 \pm 0.01$ & $1.41 \pm 0.01$ \\
\hline $505-1-1,6$ & 0.1 & $3.85 \pm 0.01$ & 2.98 \\
\hline $2-5,134$ & 7.8 & $2.62 \pm 0.01$ & 2.96 \\
\hline $2-6,131$ & 9.3 & $3.99 \pm 0.01$ & $2.13 \pm 0.04$ \\
\hline $3-5,144$ & 17.4 & $4.80 \pm 0.06$ & $1.97 \pm 0.01$ \\
\hline $5-7,38$ & 38.4 & $5.55 \pm 0.07$ & 1.84 \\
\hline $7-5,140$ & 55.4 & $6.32 \pm 0.03$ & $2.15 \pm 0.04$ \\
\hline $7-6,141$ & 56.9 & 6.82 & 1.48 \\
\hline $9-4,37$ & 71.9 & $5.18 \pm 0.06$ & $1.81 \pm 0.04$ \\
\hline $11-5,120$ & 102.7 & $2.53 \pm 0.02$ & $3.54 \pm 0.06$ \\
\hline $12-5,5$ & 111 & $6.03 \pm 0.04$ & $3.53 \pm 0.04$ \\
\hline $15-6,98$ & 142 & 6.28 & $2.34 \pm 0.03$ \\
\hline $17-6,140$ & 171 & $7.55 \pm 0.06$ & $1.33 \pm 0.01$ \\
\hline $18-6,50$ & 179.5 & 6.02 & $1.58 \pm 0.03$ \\
\hline $20-8,31$ & 201 & 8.04 & $1.19 \pm 0.01$ \\
\hline $21-6,120$ & 209 & $4.89 \pm 0.01$ & 2.12 \\
\hline $22-7,40$ & 219 & $9.03 \pm 0.01$ & 1.18 \\
\hline $24-1,0$ & 228.5 & $8.45 \pm 0.04$ & 1.24 \\
\hline $24-3,29$ & 231.8 & $7.79 \pm 0.04$ & $1.23 \pm 0.01$ \\
\hline
\end{tabular}

components and (2) sample heterogeneity due to the presence of organisms may contribute to $P_{1}$.

The P.I. values in this work can be compared with those from a previous study of the Gulf of Mexico (South Padre Island, Huc and Hunt, 1980) in order to obtain a more quantitative correlation with geothermal history. P.I. values for South Padre Island increase rapidly above 0.1 at a depth of about 3000 meters, where the formation temperature is about $120^{\circ} \mathrm{C}$. The South Padre Island sediments reach P.I. levels of 0.2 at a depth of about 3660 meters, where the formation temperature is about $135^{\circ} \mathrm{C}$. These sediments are somewhat older (Miocene) than those recovered from Sites 504 and 505. Thus, a comparison of P.I. values would indicate that sediments at depths below 100 meters at Site 504 and below 220 meters at Site 505 have been exposed to temperatures high enough to generate petroleum. If the current bottom hole temperatures of $9^{\circ} \mathrm{C}$ and $59^{\circ} \mathrm{C}$ are the highest to which these sediments have ever been ex- posed, the high P.I. values at Site 504 and in lower sections of Site 505 may be due to hydrocarbon migration.

The P.I. values at Site 504 are also anomalous in comparison to sediments in the Guyamas Basin of the Gulf of California (DSDP Leg 64), an area where young sediments have been exposed to geothermal circulation and magmatic intrusions as a result of their proximity to an active spreading center. The sediments from Sites 477 and $481 \mathrm{~A}$ are young diatomaceous oozes similar to the sediments at Sites 504 and 505. Some have been exposed to thermal alteration via the intrusion of magmatic sills. Most of the samples show P.I. values considerably below 0.1 (usually about 0.01 ), indicating that the sill intrusions have had very little effect at distances greater than 10 meters from the sill (Whelan and Hunt, in press). Sediments from below a dolerite sill at Site 477 , which show values greater than 0.2 , are an exception. All of the latter samples were taken from hydrothermally altered muds very close to an active spreading center (bottom hole temperatures in excess of $300^{\circ} \mathrm{C}$; Einsele et al., 1980). These results suggest that hydrothermal circulation may have been important at Site 504 in the past, raising the sediments to temperatures much higher than those currently observed (contrary to current hypotheses on the geothermal history of this region-see Langseth et al., this volume).

It is assumed in these arguments that the type of organic matter in these sediments remains roughly constant with sample depth. It is well known that different types of organic matter (for example, sapropelic versus woody) require different conditions of time and temperature to generate equivalent amounts of hydrocarbon (see Hunt, 1979; Tissot and Welte, 1978). The shipboard examination of sediments from Sites 504 and 505 showed predominantly marine organic material, so major changes in the type of organic matter were not expected to be a problem in these studies. However, the TDPGC method allows a more rigorous test of this assumption via examination of the capillary GC patterns of the cracked hydrocarbons that comprise $\mathrm{P}_{2}$. In past studies from this laboratory, it has been observed that a pattern of 100 to 400 peaks remains fairly constant if there is no major change in sediment type. For example, the $\mathrm{P}_{2}$ capillary GC pattern for the South Padre Island samples stays constant throughout the 4000 -meter section, even in the deepest sediments, where organic matter has passed through the maximum petroleum generation zone (Huc and Hunt, 1980; Huc et al., 1981). Figures 5 and 6 show that the organic matter at Site 504 (and by inference Site 505) is not as homogeneous as that found in South Padre Island. The patterns for the shallowest samples at Sites 504 and 505 (not shown) are very similar. In addition, the patterns for certain samples at Site 504 (e.g., Samples 504-18-3, 89 m; 504-49-1, $218 \mathrm{~m}$; and 504-53-2, $236 \mathrm{~m}$ ) are similar, although the latter two samples are leaner in organic carbon than the shallower sample. These three samples all have production indices less than 0.1 (Fig. 3). However the GC pattern for Sample 504-52-1 (231 m) (Fig. 6) is completely different. The pattern for Sample 504-18-3 (89 m) is repeated below it for comparison. Sample 504-52-1 (231 

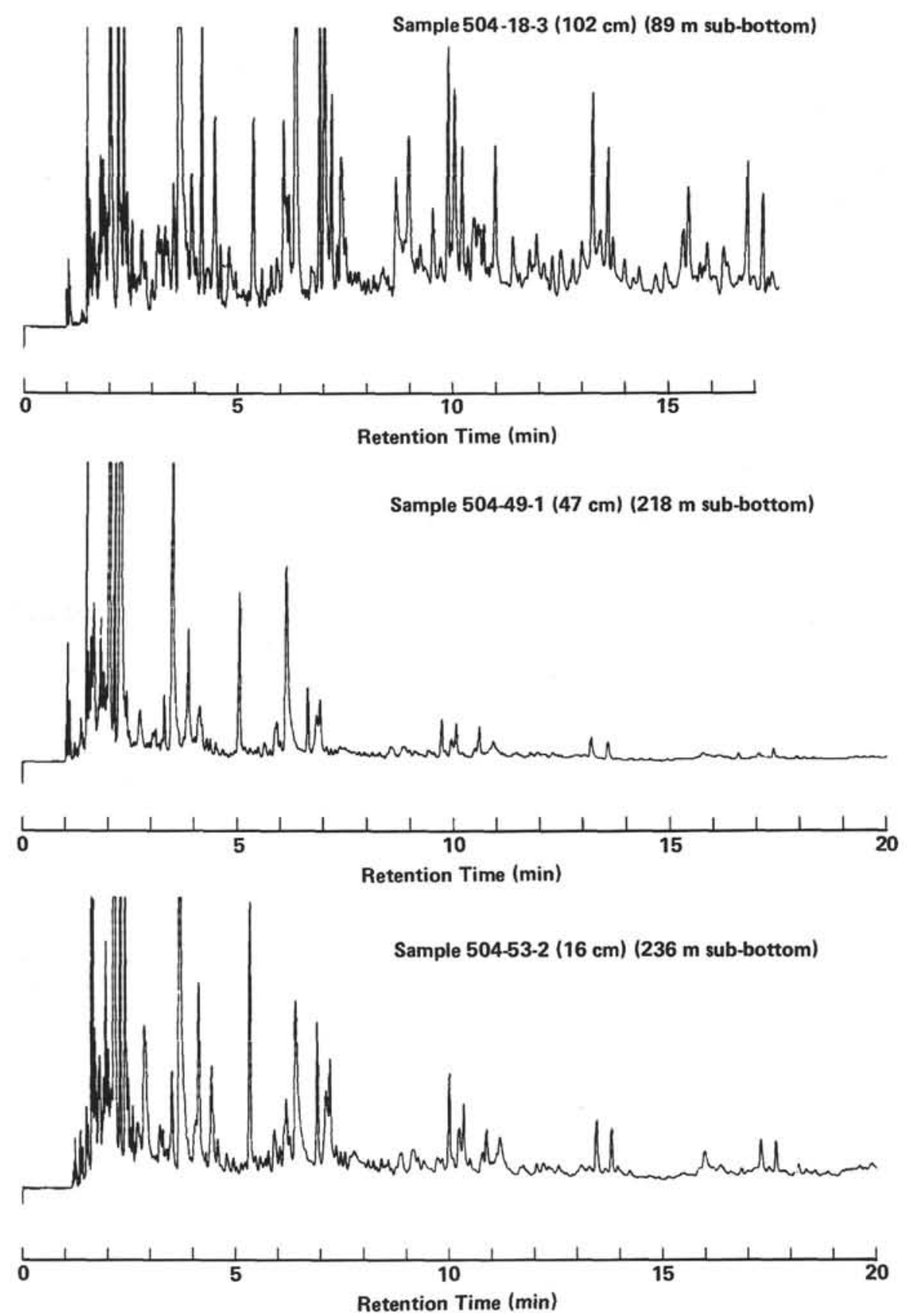

Figure 5. Comparison of similar capillary GC patterns for $\mathrm{P}_{2}$ for some of the circled data in Figure 2. Compound range: $\mathrm{C} 7$ to $\mathrm{C} 18$.

m) occurs in a chert layer and shows a high P.I. value (0.2); it is indicated by one of the boxes in Figure 2.

The samples with $\mathrm{P}_{2}$ capillary GC patterns that have been examined are indicated by the circles and boxes in Figure 2. The results from this preliminary study indicate that samples that show generally low production indices (below 0.1; circles) have the same capillary GC pattern and are made up of one type of organic matter. The samples that have P.I. values greater than 0.1 (in some cases greater than 0.2 ; boxes) show capillary GC patterns that are different from those in the first group of samples and different from each other. They also seem to be leaner in cracked $P_{2}$ components than the first group of samples. The data suggest that a comparison of P.I. values may only be valid for samples with similar organic matrices as revealed by the $\mathrm{P}_{2}$ capillary GC patterns. The results also suggest caution in the application of P.I. values in petroleum source rock studies until it is determined that the organic matrix stays relatively constant.

If the P.I. values of sediments with similar organic matrices as indicated by the capillary GC patterns are compared, the results are in better agreement with other temperature data. Thus, if only the circled samples in Figure 2 are compared, the P.I. values at Site 505 (excluding the two surface samples, which may be anoma- 


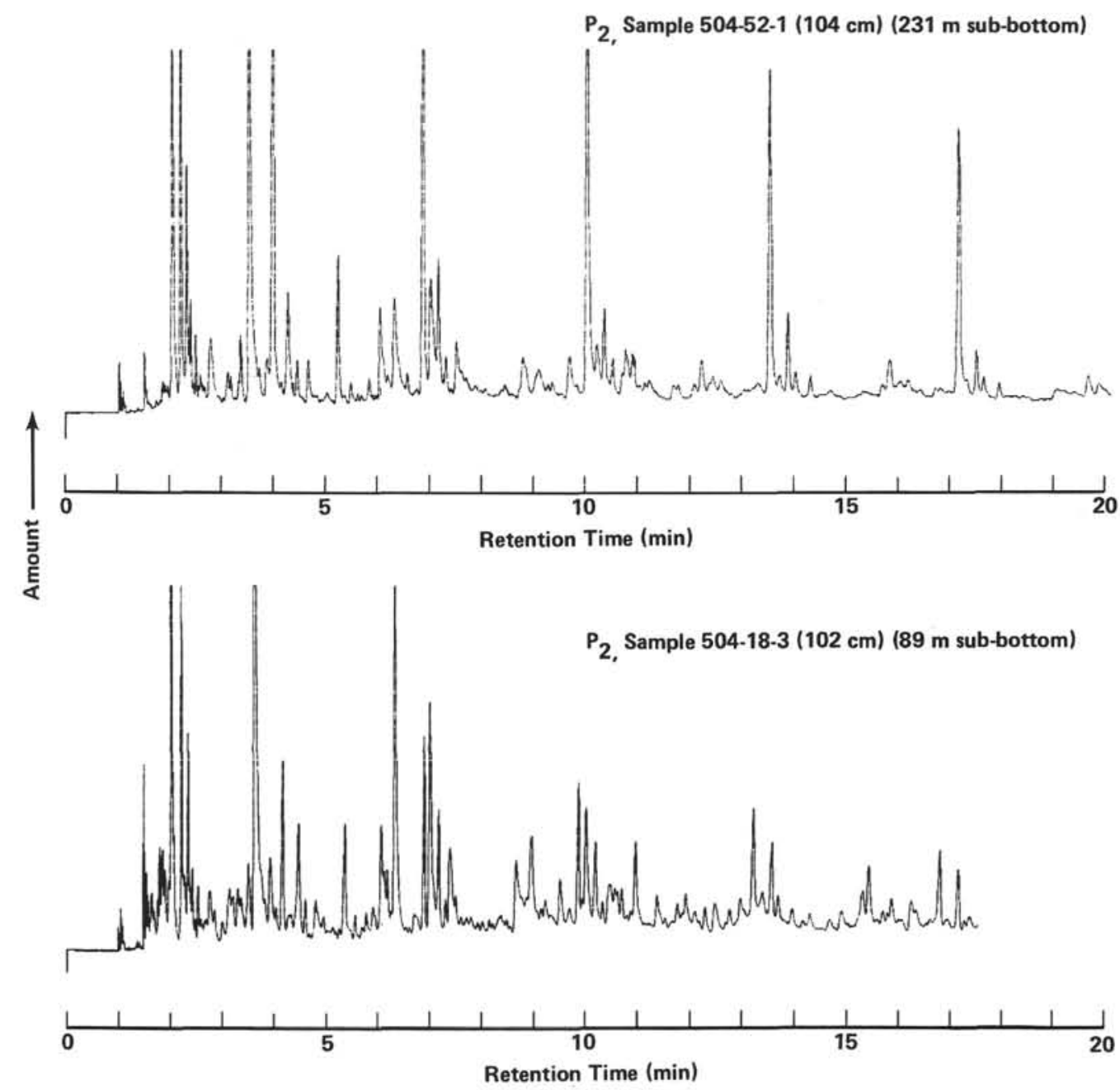

Figure 6. Comparison of dissimilar capillary GC $\mathrm{P}_{2}$ patterns for two sediments from Site 504. Sample 504-18-3 $(102 \mathrm{~cm})$ is typical of a circled point in Figure 2; Sample 504-52-1 $(104 \mathrm{~cm})$ is typical of a boxed point in Figure 2. Compound range: same as Figure 5.

lous, as discussed previously) are lower than those at Site 504. In addition, the values for the circled samples at Site 504 are in the neighborhood of 0.1 , which is reasonable for the current bottom hole temperature of $59^{\circ} \mathrm{C}$.

The question arises as to why the P.I. values and organic matrices for the other samples at Sites 504 and 505 are so different. To examine how the magnitude of $P_{1}$, $\mathrm{P}_{2}$, and the quantity of organic carbon influence P.I., all four parameters were plotted as a function of depth; the results are shown in Figures 7 and 8. Apparently, P.I. values are artificially high for samples with very low $\mathrm{P}_{2}$ values - the bottom two samples at Site 505, for example, and all samples below 100 meters at Site 504 .

At both sites, organic carbon appears to correlate with $\mathrm{P}_{2}$. This relationship is shown more clearly in Figures 7 and 8 , where organic carbon is plotted against $P_{2}$. The correlation coefficients are $\mathbf{0 . 8 4}$ for Site 504 and 0.96 for Site 505 . In both cases, the two surface samples (shown with crosses) and a small number of other anomalously high points (indicated with the circles) have been excluded from the correlation. These calculations suggest the absence of sediments with grossly different hy-

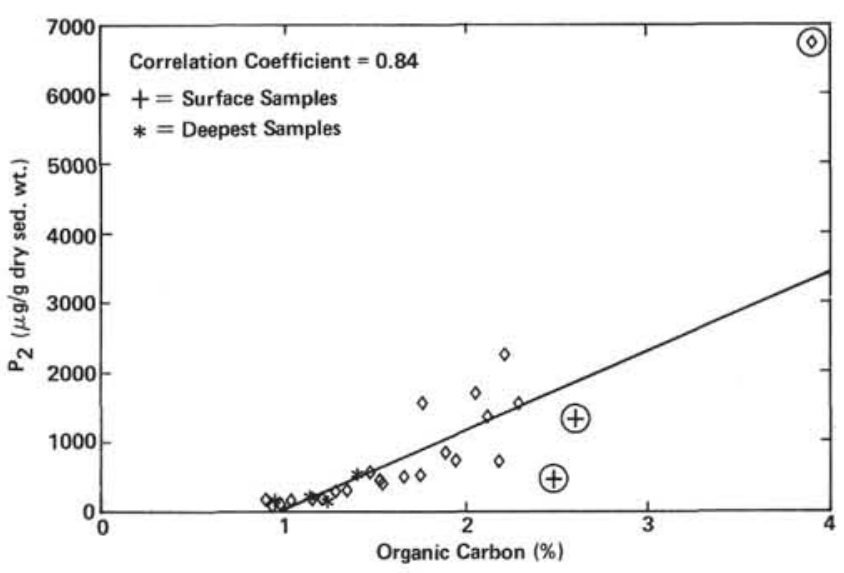

Figure 7. Organic carbon versus $P_{2}$ at Site 504. The circled samples were not included in calculating in the linear regression line $\left[\mathrm{P}_{2}=\right.$ 1132 (Organic carbon) - 1085].

drocarbon-generating potential even when the organic matrix changes. Thus, the high P.I. values below 100 meters at Site 504 may reflect a past hydrothermal circulation in these sediments that caused both an alteration 


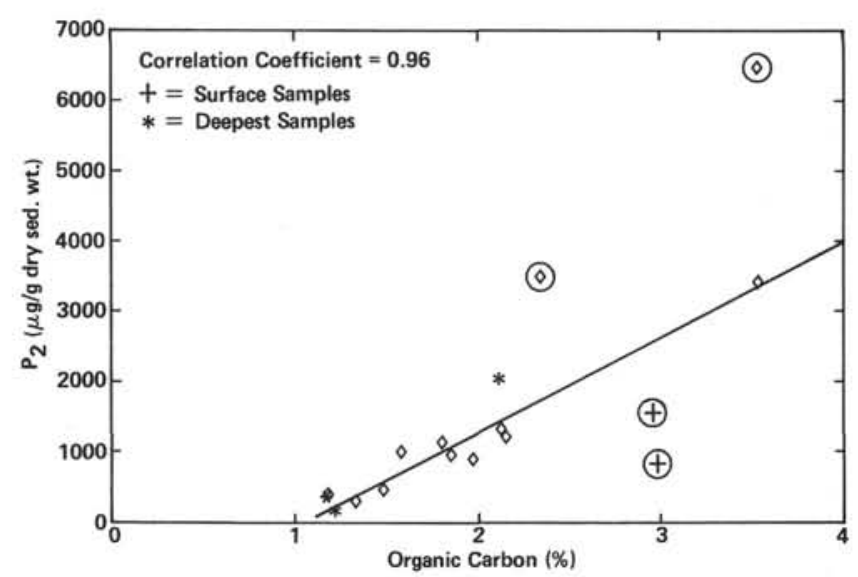

Figure 8. Organic carbon versus $P_{2}$ at Site 505. The circled samples were not included in calculating the linear regression line $\left[\mathrm{P}_{2}=\right.$ 1347 (Organic carbon) - 1382].

in the organic matter (as reflected by the $\mathrm{P}_{2}$ capillary GC pattern) and an increase in the proportion of absorbed hydrocarbons in relation to total organic matter, as reflected by P.I.

One piece of evidence that supports the existence of such hydrothermal circulation is the large increase in $P_{1}$ between 90 and 130 meters at Site 504 (see Fig. 3). The increase is particularly noticeable because $P_{1}$ values are otherwise fairly constant for the site. This increase occurs at the top of a section where $\mathrm{P}_{2}$ values drop to very low levels. The reason for this increase in $P_{1}$ may be the migration of hydrocarbons to the zone just above the active hydrothermal circulation. Such migration was observed in the Gulf of California sediments mentioned previously.

An alternative explanation may be differences in past biological activity in the sediments as reflected in the general degree of burrowing in the cores (Beiersdorf and Natland, this volume). Bioturbation is intense at depths below 102 meters sub-bottom at Site 504. This is the same region in which $\mathrm{P}_{2}$ values generally drop below 500 $\mu \mathrm{g} / \mathrm{g}$, as shown in Figure 3, and organic carbon generally decreases, as shown in Table 1 and Figure 3. In the shallower sediments, which show both generally higher $\mathrm{P}_{2}$ and organic carbon values, the sediments are described as being only slightly or moderately burrowed. At Site 505, the sediments generally appear to be more anoxic, as shown by the odor of $\mathrm{H}_{2} \mathrm{~S}$ and the general lack of burrowing in the cores in the depth interval between 8 and 140 meters. In the same interval, $P_{2}$ and organic carbon values are high, with $\mathrm{P}_{2}$ values that are generally above $1000 \mu \mathrm{g} / \mathrm{g}$ and, in the interval between 100 and 150 meters, as high as 6000 (Fig. 4). In deeper sections, burrowing activity was intense. In these sections, $P_{2}$ values drop to levels below 1000 , as was found for deeper sections of Site 504. Thus, it is possible that P.I. and the $P_{1}$ and $P_{2}$ patterns reflect the presence of "edible" (reactive) carbon in shallow sediments.

A measure of the degree to which the organic carbon in these sediments is inert to hydrocarbon generation can be obtained from Figures 7 and 8 . In both cases, $\mathrm{P}_{2}$ plotted against organic carbon intercepts the organic carbon axis at about $1 \%$ organic carbon. This indicates that $1 \%$ of the organic carbon in these sediments could not generate hydrocarbons under any condition of heat and temperature. Another way to state the relationship is that $1 \%$ of the organic carbon at these sites possesses too little hydrogen (is too oxidized) to be capable of hydrocarbon generation. If it is assumed that the oxidation was primarily carried out at the time of sediment deposition by burrowing organisms, $1 \%$ organic carbon is the amount of carbon not utilized by these animals. Thus, the plot of $\mathrm{P}_{2}$ versus organic carbon may also be a measure of the amount of organic carbon that is not biologically utilizable. Such a measurement may be valuable for other marine sediments because it is difficult to obtain a measure of biologically useful organic carbon in these systems (see, for example, Menzel and Ryther, 1970; Riley and Chester, 1971, p. 211).

It is also possible that the $1 \%$ inert carbon represents charcoal from metamorphosed organic matter that has been heated to temperatures in excess of $200^{\circ} \mathrm{C}$. This possibility could be examined via an independent measure of thermal maturity, such as kerogen analysis. In the absence of these measurements, however, biological reworking seems the more reasonable explanation for these sediments because there is no sedimentological evidence for coaly particles (Beiersdorf and Natland, this volume).

\section{CONCLUSIONS}

1. Thermal differences between Deep Sea Drilling Project Sites 504 and 505 near the Costa Rica Rift are reflected by different degrees of thermal hydrocarbon generation as indicated by the production index (P.I.). P.I. values reflect past thermal history when compared for sediments that contain similar types of organic matter as revealed by the capillary gas chromatography (GC) pattern of cracked $\mathrm{P}_{2}$ hydrocarbons.

2. Some highly burrowed sediments from these sites gave low values of $P_{2}$, resulting in unreasonably high values of P.I. Capillary GC patterns for $P_{2}$ show that burrowed sediments were generally different from the unburrowed sections. It is postulated that the low $\mathrm{P}_{2}$ values result from biological reworking that occurred at the time of deposition.

3. Organic carbon levels generally correlate with $\mathrm{P}_{2}$ at both sites. The intercept showed a $\mathrm{P}_{2}$ value of zero when organic carbon was $1 \%$. This measurement may show that $1 \%$ of the organic carbon in these samples is inert to hydrocarbon generation under any conditions of time and temperature. This value may reflect the amount of nonbiodegradable or inert organic carbon in these sediments.

4. High values of $P_{1}$ between sub-bottom depths of 90 and 130 meters at Site 504 may represent migrated hydrocarbons. We suggest hydrothermal circulation as one mechanism for accomplishing such migration.

\section{ACKNOWLEDGMENTS}

We would like to thank Christine Burton and Martha Tarafa for the analyses, Mike Mottl for helping us to interpret our results, and Susan Palmer and Kenneth Peters for reviewing the manuscript. The 
work is Woods Hole Oceanographic Institution Contribution No.

5013. It was supported by NSF Grant No. OCE-20-19508.

\section{REFERENCES}

Barker, C., 1974. Pyrolysis techniques for source-rock evaluation. Am. Assoc. Pet. Geol. Bull., 58:2349-2361.

Claypool, G. E., and Reed, P. R., 1976. Thermal-analysis technique for source-rock evaluation: quantitative estimate of organic richness and effects of lithologic variation. Am. Assoc. Pet. Geol. Bull., 60:608-626.

Einsele, G., Gieskes, J. M., Curray, J., Moore, D. M., Aguayo, E., Aubry, M.-P., Fornari, D., Guerrero, J., Kastner, M., Kelts, K., Lyle, M., Matoba, Y., Molina-Cruz, A., Niemitz, J., Rueda, J., Saunders, A., Schrader, H., Simoneit, B., and Vacquier, V., 1980. Intrusion of basaltic sills into highly porous sediments, and resulting hydrothermal activity. Nature, 283:441-445.

Espitalié, J., Madec, M., Tissot, B., Mennig, J. J., and Leplat, P., 1977. Source rock characterization method for petroleum exploration. Offshore Technology Conference [Proceedings], 9(No. 3): 439-444.

Giraud, A., 1970. Application of pyrolysis and gas chromatography to geochemical characterization of kerogen in sedimentary rock. Am. Assoc. Pet. Geol. Bull., 54:439-455.
Huc, A. Y., and Hunt, J. M., 1980. Generation and migration of hydrocarbons in offshore South Texas Gulf Coast sediments. Geochim. Cosmochim. Acta, 44:1081-1089.

Huc, A. Y., Hunt, J. M., and Whelan, J. K., 1981. The organic matter of a Gulf coast well studied by a thermal analysis-gas chromatography technique. J. Geochem. Explor., 15:671-681.

Hunt, J. M., 1979. Petroleum Geochemistry and Geology: San Francisco (W. H. Freeman).

Menzel, D. W., and J. H. Ryther, 1970. Distribution and cycling of organic matter in the oceans. In Hood, D. W. (Ed.), Symposium on Organic Matter in Natural Waters: [College, Alaska] (Univ. Alaska), pp. 31-54.

Riley, J. P., and Chester, R., 1971. Introduction to Marine Chemistry: London (Academic Press).

Tissot, B. P., and Welte, D. H., 1978. Petroleum Formation and Occurrence: Berlin (Springer-Verlag).

Whelan, J. K., and Hunt, J. M., in press. $C_{1}-C_{8}$ hydrocarbons in Leg 64 sediments, Gulf of California. Init. Repts. DSDP, 64, Pt. 2: Washington (U.S. Govt. Printing Office).

Whelan, J. K., Hunt, J. M., and Huc, A. Y., 1980. Applications of thermal distillation-pyrolysis to petroleum source rock studies and marine pollution. J. Anal. Appl. Pyrolysis, 2:79-96. 